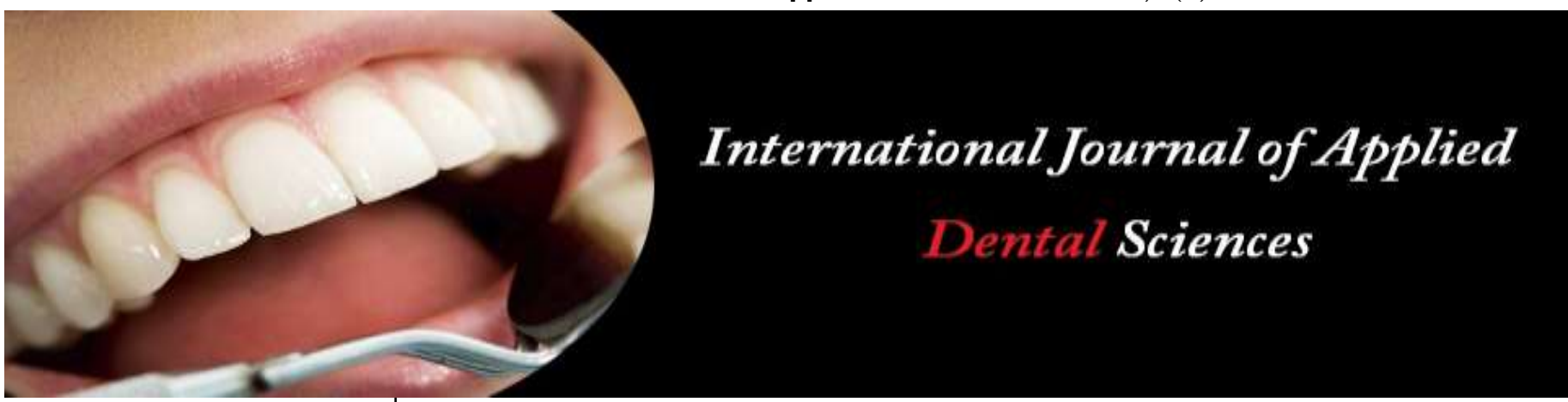

ISSN Print: 2394-7489

ISSN Online: 2394-7497

IJADS 2021; 7(2): 240-243

(C) 2021 IJADS

www.oraljournal.com

Received: 28-01-2021

Accepted: 15-03-2021

Vijeta Angural

Department of Orthodontics \&

Dentofacial orthopaedics

Govt. College of Dentistry,

Indore, Madhya Pradesh, India

Sandhya Jain

MDS Professor \& HOD

Department of Orthodontics \&

Dentofacial orthopaedics

Govt. College of Dentistry,

Indore, Madhya Pradesh, India

Madhu S Ratre

Professor \& HOD,

Department of Periodontology \&

Implantology, Govt. College of

Dentistry, Indore, Madhya

Pradesh, India

Ankit Patel

Dental Assistant, NJ smiles

Dental Office Avenel, New

Jersey, USA

Hiral Dholakiya

Private Practitioner,

Varachha Surat, Gujarat, India

Rubab Kahlon

Dental Assistant, Brockstarr

Dental, Whitby

Corresponding Author:

Vijeta Angural

Department of Orthodontics \&

Dentofacial orthopaedics

Govt. College of Dentistry,

Indore, Madhya Pradesh, India

\section{Management of impacted mandibular canine by orthodontic treatment with apical repositioning flap: A case report}

\author{
Vijeta Angural, Sandhya Jain, Madhu S Ratre, Ankit Patel, Hiral \\ Dholakiya and Rubab Kahlon
}

DOI: https://doi.org/10.22271/oral.2021.v7.i2d.1215

\section{Abstract}

The occurrence of impacted mandibular canine is less common than impacted maxillary canine. The causes of impacted mandibular canines are inadequate space, premature loss of the primary dentition, excessive crown length, hereditary factors, tumors and traumas. This case report describes the diagnosis and treatment of impacted mandibular canine by surgical exposure by apically repositioned flap and orthodontic positioning of it. The combined effect of surgical exposure by apically repositioned flap of impacted mandibular canine and orthodontically correcting its position shows satisfactory results in improved smile and healthy attached gingiva.

Keywords: Apically repositioned flap, impaction, mandibular canine, Multiloop wire, orthodontic traction

\section{Introduction}

The impaction of tooth may be a retardation or halt within the normal process of eruption. According to Kuftinec and Shapira, impaction is a condition in which a tooth is embedded in the alveolus so that its eruption is impeded and it is locked in position by bone or by adjacent teeth ${ }^{[1]}$. In current perspective, an impacted tooth is one "whose eruption is considerably delayed, and for which there is clinical or radiographic evidence that further eruption may not take place" ${ }^{[2]}$. Canine is taken into account as being impacted if it is interrupted after complete root development or if the contralateral tooth is erupted for a minimum of 6 months with complete root formation ${ }^{[3]}$.

Etiology: Those teeth failed to emerge to oral cavity due to various reasons like insufficient space, early loss of primary teeth with eventual closure of space, crowding of arches rotation of tooth buds, excessive fibrous tissue over an erupting tooth etc. are termed as impacted teeth. Of all the reasons eruption cysts being relatively rare cause of impaction ${ }^{[4]}$. Local biomechanical impediments, and secondarily from childhood maxillofacial or dentoalveolar trauma, reconstructive surgery of the facial skeleton, malposition of an adjacent tooth, thick osseous or mucosal tissues above teeth, insufficiently developed jaw bone or the difference within the rate of development and maturation of jaw bones and teeth respectively, disturbances in eruption and direct or indirect effects of cysts or neoplasm of jaws are always in list of reasons for impaction ${ }^{[5]}$.

Prevalence: The prevalence of impacted mandibular canines varies from $0.05 \%$ to $0.4 \%$, which is less frequent than impaction of maxillary canines, ranging from $0.9 \%$ to $2.2 \%{ }^{[6,7]}$.

Sequelae of canine impaction: A large number of completely impacted teeth may be retained when asymptomatic ${ }^{[8]}$. However, Bishara et al. suggested the following sequelae of canine impaction ${ }^{[9,10]}$

- Labial or lingual malpositioning of the impaction

- Migration of the neighboring teeth and loss of arch length 
- External root resorption of the impacted tooth also because the neighboring teeth

- Infection particularly with partial eruption leading to pain and trismus

- Referred pain

Impacted mandibular canines are also more likely to be located on the labial aspect of the dental arch than are maxillary canines, and the removal of impacted teeth routinely involves an intraoral surgical approach ${ }^{[11]}$.

Case Presentation: An 14 year old male patient with chief complaint of irregularly placed upper front teeth and wanted to get the treatment done for the same. He was physically healthy and had no past history of medical or dental trauma. No signs or symptoms of temporomandibular joint dysfunction were noted at the initial examination. On extra oral examination it was observed that the patient had no gross asymmetries. Patient had a mesoprosopic face with convex profile and competent lips and normal mentolabialsulcus. The smile analysis revealed a reduced incisor display with a nonconsonant smile. (Figure 1) On intra oral examination (Figure 2), it was observed that the patient had Class II division 2 incisor relationship and End -on molar relation on right side and Angle's Class I molar relation on left. The mandibular dental midline was deviated by $4 \mathrm{~mm}$ to the left side. Cephalometrically (Figure $3 \mathrm{a}$ and $3 \mathrm{~b}$ ) the patient had a Class II skeletal relationship (ANB angle: $4^{\circ}$ ) A vertical growth pattern was seen (FMA: $31.5^{\circ}$ ). Maxillary incisors were retruded and retroclined with the upper incisor to NA at -1.5 and $10^{\circ}$. The lower incisors were retruded and retroclined and the lower incisor at $2 \mathrm{~mm}$ and $19^{\circ}$ to $\mathrm{NB}$, with an IMPA of $93^{\circ} 87.5^{\circ}$ (Table I). The panoramic radiograph showed all permanent teeth present, except left mandibular unerupted third molar. The mandibular left canine was impacted. The labial position of the impacted mandibular canine was confirmed with the help of mandibular occlusal radiograph.

\section{Treatment objectives}

- Align and level the maxillary and mandibular dental arches

- Surgical exposure of 33 followed by orthodontic traction

- Obtain normal overjet and overbite

- Achieve bilateral Class I canine occlusion

- Achieve bilateral Class I molar occlusion and attain optimum soft tissue relationship

Treatment Progress: The aesthetic concern and the patient's desire called in for a challenging solution for an unusual impacted mandibular canine treatment to align into its ideal position in the arch. On considering the diagnostic criteria, treatment plan was formulated for the patient involving surgical uncovering of the impacted mandibular canine followed by traction. The treatment was initiated using an MBT-022X028"slot pre-adjusted edgewise appliance. Initially, multiloop wires were used in both the maxillary and mandibular arch to create space. (Figure 4) Then Archwires was progressed to flexible NiTi wires and after that stiffer Stainless Steel wires. When enough space was gained in lower arch, surgical exposure by Apically repositioned flap of lower left canine was done (Figure 5). This increases healthy band of keratinized gingiva. Furthermore, this prevents gingival recession and/or periodontal defects. Canine bracket was bonded to the canine during the procedure and orthodontic traction was applied using ligature wire. Settling was done with 0.014" Stainless Steel archwire.

\section{Treatment results}

The facial aesthetic was improved. The smile was enhanced and the consonant smile arc was achieved. Intraorally, ideal overjet and overbite was achieved with Class I molar and canine relationship (Figure 6). Post treatment lateral Cephalogram (Table 1) showed the position of upper and lower incisors were improved, upper incisor at $27^{\circ}$ and $4 \mathrm{~mm}$ to NA and the lower incisor at $27^{\circ}$ and $6 \mathrm{~mm}$ to $\mathrm{NB}$ with an IMPA of $97^{\circ}$. At the end of the treatment period, a functional occlusion was observed. The clinical results included normal overjet and overbite, adequate intercuspation, nearly coincident midlines. The patient was satisfied and the case was finalized.

\section{Discussion}

The most important step in the management of impacted teeth is the diagnosis and localization of impacted teeth. Failure of eruption of the mandibular canine is an unusual event. ${ }^{12}$ There are limited number of studies revealing the frequency of occurrence of mandibular canine impactions and is regarded as a much rarer phenomenon. Failure of tooth eruption may be the consequence of local factors or systemic factors. Local factors may include mechanical obstruction (by a supernumerary tooth, cyst, or tumor); insufficient space in the dental arch or to the premature loss of deciduous teeth or a tooth arch size discrepancy. Systemic factors such as genetic disorders, endocrine deficiencies, and previous irradiation of the jaws are also associated with a failure of tooth eruption. In systemic conditions multiple teeth are usually impacted. In most cases, however, the specific explaination for failure of eruption remains unknown ${ }^{[11]}$. Delayed tooth eruption can cause necrosis of the pulp, ankylosis and external apical root resorption. It is difficult to predict when resorption will start. Thus, all impacted teeth should be considered having a high risk of external apical root resorption or damage to the adjacent tooth. So, radiographic examinations should be used to observe these risks. Commonly, orthopantomograph is used [13]. In our case, the canine was in favourable position, and since canines are considered important foundations in the dental arch, we decided to orthodontically bring it into its ideal position. Management of impacted canines is often challenging situation for an orthodontist. Two common methods that have been considered for impacted canines are the closed- eruption technique and the open- eruption technique. In this case closed eruption technique was planned. Adequate space should be created prior to application of traction forces to the canine. A rigid stainless steel working wire is required before the traction is applied to avoid undesirable effects on the neighbouring dentition. The archlength deficiency in mandibular arch was resolved and slight arch widening took place. The treatment difficulty and prospect of complications, which impede with duration of the traction, are related to age, occlusal movement, apical movement, angulation and mesiodistal location of the impacted canine's crown, complex relationship between canine's crown and midline, and presence of transposed lateral incisor or first premolar ${ }^{[14]}$. 


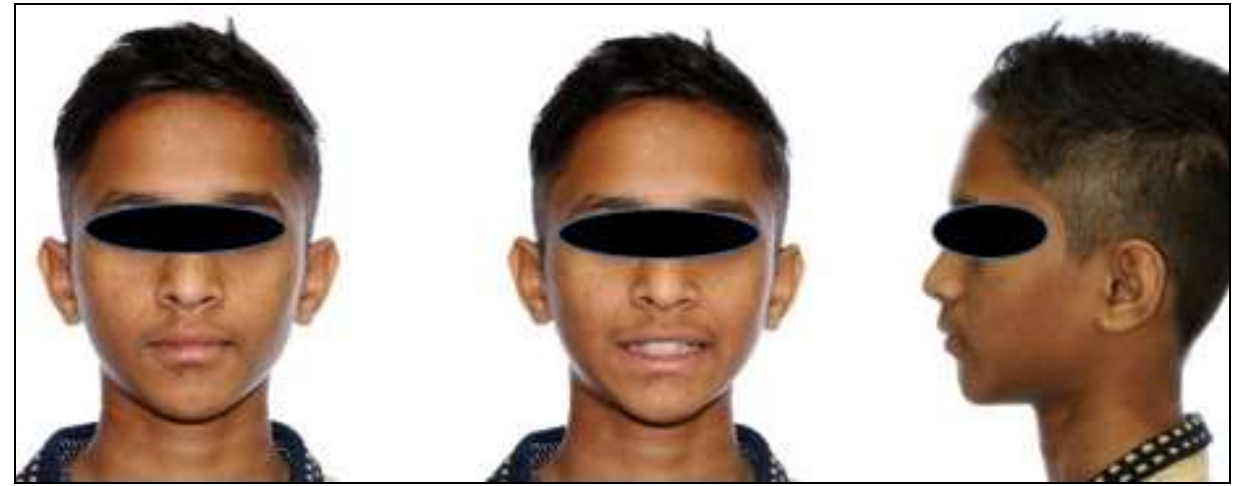

Fig 1: Pre-treatment Extraoral photographs

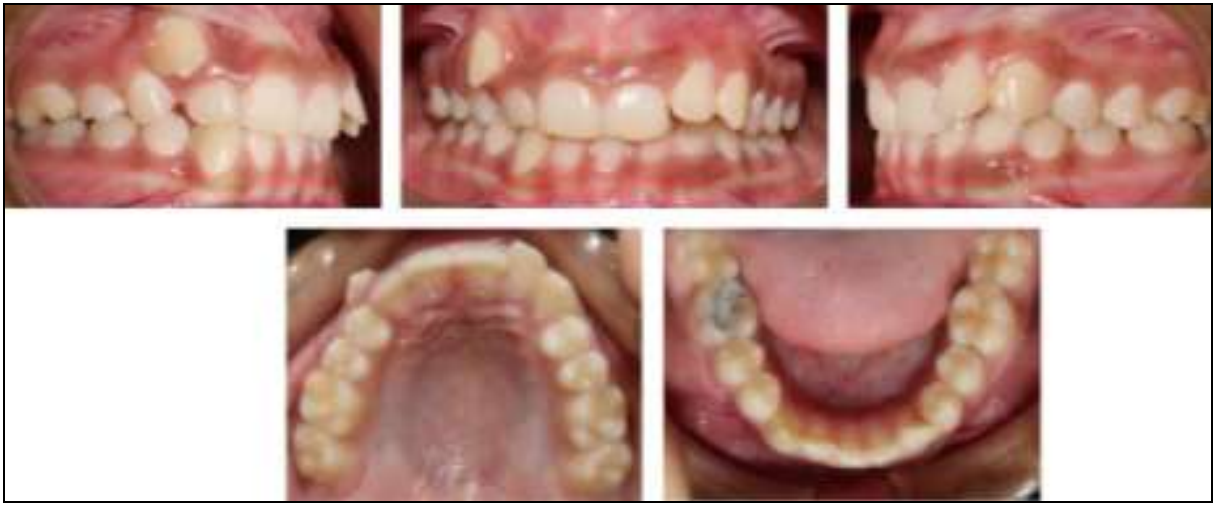

Fig 2: Pretreatment intraoral photographs

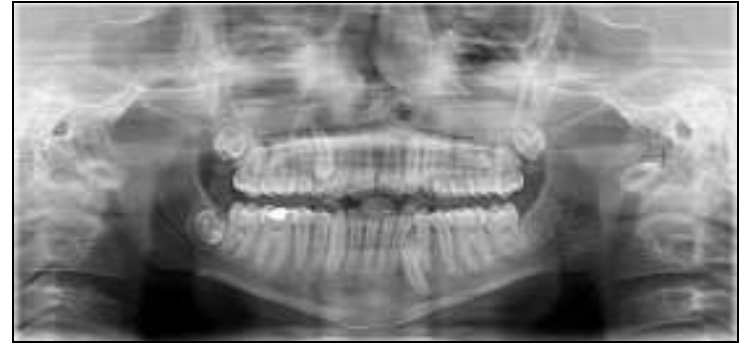

Fig 3a: Pretreatment lateral cephalogram

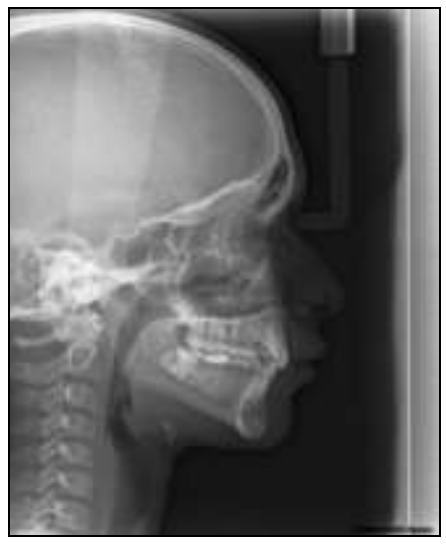

Fig 3b: Pretreatment OPG

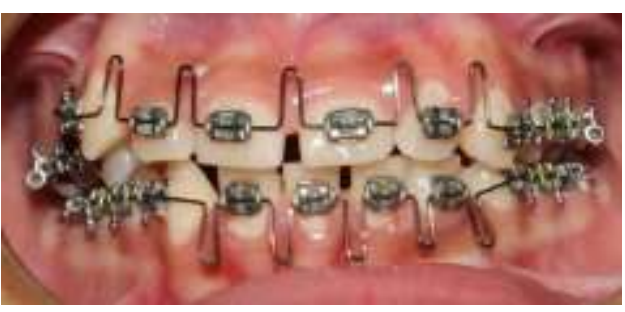

Fig 4: Multiloop AJ Wilcock wires in both arches

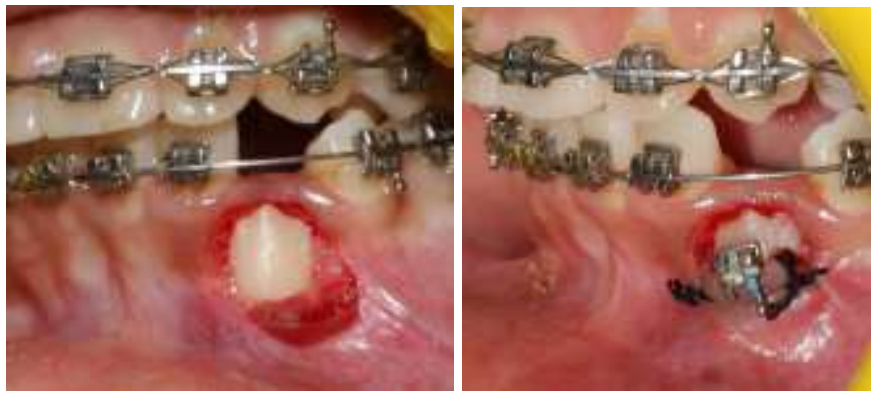

Fig 5: Surgical exposure by Apically repositioned flap of mandibular canine and bracket placement

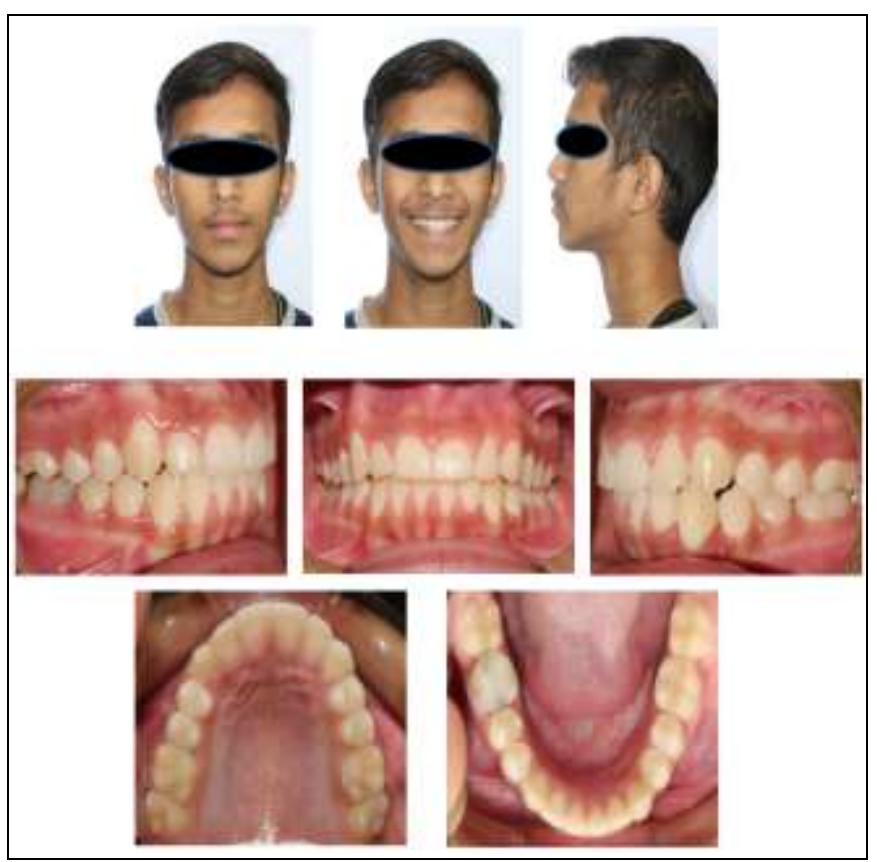

Fig 6: Post treatment extraoral and intraoral photographs 
Table I: Comparison of pre and post treatment cephalometric readings

\begin{tabular}{|c|c|c|}
\hline Measurement & $\begin{array}{c}\text { Pre } \\
\text { treatment }\end{array}$ & $\begin{array}{c}\text { Post- } \\
\text { treatment }\end{array}$ \\
\hline SNA 82。 & $80^{\circ}$ & $80^{\circ}$ \\
\hline SNB 80॰ & $76^{\circ}$ & $75.5^{\circ}$ \\
\hline ANB 2。 & $4^{\circ}$ & $4.5^{\circ}$ \\
\hline WITS $-1 / 0$ & $+7.5 \mathrm{~mm}$ & $2 \mathrm{~mm}$ \\
\hline FMA 25० & $31.5^{\circ}$ & $32.5^{\circ}$ \\
\hline U1-NA linear $4 \mathrm{~mm}$ & $-0.5 \mathrm{~mm}$ & $4 \mathrm{~mm}$ \\
\hline U1-NA angle 22。 & $10^{\circ}$ & $27^{\circ}$ \\
\hline L1-NB linear $4 \mathrm{~mm}$ & $2 \mathrm{~mm}$ & $6 \mathrm{~mm}$ \\
\hline L1-NB angle 25。 & $19^{\circ}$ & $30.5^{\circ}$ \\
\hline Interincisal 130+/_5o & $147^{\circ}$ & $119^{\circ}$ \\
\hline IMPA $95 \pm 5 \circ$ & $87.5^{\circ}$ & $97^{\circ}$ \\
\hline L1-MP 49/42+/-3mm & $34^{\circ}$ & $37^{\circ}$ \\
\hline L6-MP 38/33+/-3mm & $28^{\circ}$ & $28.5^{\circ}$ \\
\hline $\begin{array}{l}\text { Angle of facial convexity (G- } \\
\text { Sn-Pg ) } 12 \pm 4\end{array}$ & $18^{\circ}$ & $18.5^{\circ}$ \\
\hline Upper lip- E line & $1 \mathrm{~mm}$ & $1.5 \mathrm{~mm}$ \\
\hline Lower lip- E line & $1 \mathrm{~mm}$ & $3 \mathrm{~mm}$ \\
\hline Nasolabial angle $102+/ 44 \circ$ & $99^{\circ}$ & $93^{\circ}$ \\
\hline
\end{tabular}

\section{Conclusion}

The impacted canine must be localized prior to the treatment for better access during the surgical exposure. Our results showed a satisfactory improvement in smile with healthy attached gingiva and no periodontal defect. Ideal dental relationships were obtained. The combined effect of surgical exposure by apically repositioned flap of impacted mandibular canine and orthodontically correcting its positing was instrumental in re-establishing the major components of a balanced smile for this patient, whose main concern was his unpleasant smile.

\section{References}

1. Kuftinec MM, Shapira Y. The impacted maxillary canine: I. Review of concepts. ASDC J Dent Child 1995;62(5):317-24.

2. Mason C, Papadakou P, Roberts GJ. The radiographic localization of impacted maxillary canines: a comparison of methods. Eur J Orthod 2001;23(1):25-34.

3. Lindauer SJ, Rubenstein LK, Hang WM, Andersen WC, Isaacson RJ. Canine impaction identified early with panoramic radiographs. J Am Dent Assoc 1992;123(3):91-92, 95-97.

4. Bayar R, Orta OLu, Sencimen K, Multiple impacted teeth: report of 3 cases. European journal of dentistry, 2008;2:73.

5. Duffy MT. Multiple impacted supernumerary teeth. Oral Surg 1973;35:433-434.

6. Agarwal S, Yadav S, Shah NV, Valiathan A, Uribe F, Nanda R. Correction of bilateral impacted mandibular canines with a lip bumper for anchorage reinforcement. Am J Orthod Dentofacial Orthop 2013;143:393-403.

7. D'Amico RM, Bjerklin K, Kurol J, Falahat B. Long-term results of orthodontic treatment of impacted maxillary canines. Angle Orthod 2003;73:231-238.

8. Yamaoka M, Furusawa K, FujimotoK, Uematsu T. Completely impacted teeth in dentate and edentulous jaws. Aust Dent J 1996;41:169-72.

9. Bishara SE, Kommer DD, McNeil MH, Montagano LN, Oesterle LJ, Youngquist W. Management of impacted canines. Am J Orthod 1976;69:371-87.

10. Bishara SE. Impacted maxillary canines. Am J Orthod Dentofac Orthop 1992;101:159-71.
11. Fonseca JR. Oral and Maxillofacial Surgery. Philadelphia: W. B. Saunders 2000;1:342-371

12. Camilleri S, Scerri E. Transmigration of mandibular canines - A review of the literature and a report of five cases. Angle Orthod 2003;73:753-62.

13. Kavadia-Tsatala S, Tsalikis L, Kaklamanos EG, Sidiropoulou S, Antoniades K. Orthodontic and periodontal considerations in managing teeth exhibiting significant delay in eruption. World J Orthod 2004;5:224229.

14. Cati G, Ghobadlu J, Nieri M, Clauser C. Factors associated with the duration of forced eruption of impacted maxillary canines: a retrospective study. Am J Orthod Dentofacial Orthop 2006;130:349-56. 